\title{
Adult liver transplantation in Johannesburg, South Africa (2004 - 2016): Balancing good outcomes, constrained resources and limited donors
}

E Song, ${ }^{1,2}$ MB BCh, FCP (SA), FRCP (Lond); J Fabian, ${ }^{1,2}$ MB BCh, FCP (SA), Cert Nephrology (SA); P E Boshoff, ${ }^{1}$ MB BCh, MRCP (UK), FCRad (Diag) (SA); H Maher, ${ }^{1}$ Registered Nurse; P Gaylard, ${ }^{3} \mathrm{PhD}$; A Bentley, ${ }^{4} \mathrm{MB}$ BCh, PhD; M J Hale,,${ }^{5,6} \mathrm{MB}$ BCh, FCPath (SA); S P Ngwenya, ${ }^{5,6} \mathrm{MB}$ BCh, FCPath (SA); H Etheredge, ${ }^{1,2} \mathrm{PhD}$; A Mahomed ${ }^{1,2} \mathrm{MB}$ BCh, FCP (SA), Cert Gastroenterology (SA); B Bobat, ${ }^{1,2}$ MB BCh, FCP (SA), Cert Gastroenterology (SA); B Strobele, ${ }^{1}$ MB BCh, MMed, FCS (SA); J Loveland ${ }^{1,7}$ MB BCh, FCS (SA), Cert Paed Surg; R Britz, ${ }^{1} \mathrm{MB}$ BCh, FCS (SA); J F Botha, ${ }^{1,8}$ MB BCh, FCS (SA)

${ }^{1}$ Wits Donald Gordon Medical Centre, University of the Witwatersrand, Johannesburg, South Africa

${ }^{2}$ Department of Internal Medicine, Faculty of Health Sciences, University of the Witwatersrand, Johannesburg, South Africa ${ }^{3}$ DMSA (Data Management and Statistical Analysis), Johannesburg, South Africa

${ }^{4}$ Department of Family Medicine, Faculty of Health Sciences, University of the Witwatersrand, Johannesburg, South Africa

${ }^{5}$ Division of Anatomical Pathology, School of Pathology, Faculty of Health Sciences, University of the Witwatersrand, Johannesburg, South Africa

${ }^{6}$ National Health Laboratory Service, Sandringham, Johannesburg, South Africa

${ }^{7}$ Department of Paediatric Surgery, Faculty of Health Sciences, University of the Witwatersrand, Johannesburg, South Africa

${ }^{8}$ Department of Surgery, Faculty of Health Sciences, University of the Witwatersrand, Johannesburg, South Africa

Corresponding author: J Fabian (june.fabian@mweb.co.za)

Background. Liver transplantation is the standard of care for the treatment of liver failure worldwide, yet millions of people living in subSaharan Africa remain without access to these services. South Africa (SA) has two liver transplant centres, one in Cape Town and the other in Johannesburg, where Wits Donald Gordon Medical Centre (WDGMC) started an adult liver transplant programme in 2004.

Objectives. To describe the outcomes of the adult liver transplant programme at WDGMC.

Methods. This was a retrospective review of all adult orthotopic liver transplants performed at WDGMC from 16 August 2004 to 30 June 2016 with a minimum follow-up of 6 months. The primary outcome was recipient and graft survival and the effect of covariates on survival. Kaplan-Meier survival analysis included all adults who underwent their first transplant for end-stage liver disease (ESLD) (N=275). Proportional hazards regression analysis using hazard ratios (HRs) was conducted to determine which covariates were associated with a significantly increased risk of mortality.

Results. A total of 297 deceased-donor liver transplants were performed during the study period; 19/297 (6.4\%) were for acute liver failure (ALF) and the remainder were for ESLD. The median age of recipients was 51 years (interquartile range 41 - 59), and two-thirds were male. The most common cause of ESLD was primary sclerosing cholangitis. The median follow-up was 3.2 years, and recipient survival was characterised in the following intervals: 90 days $=87.6 \%$ (95\% confidence interval (CI) $83.1-91.0), 1$ year $=81.7 \%(95 \%$ CI $76.6-85.8)$, and 5 years $=71.0 \%(95 \%$ CI $64.5-76.5)$. Allograft survival was similar: 90 days $=85.8 \%(95 \%$ CI $81.1-89.4), 1$ year $=81.0 \%(95 \%$ CI $75.8-$ $85.2)$, and 5 years $=69.1 \%(95 \%$ CI $62.6-74.7)$. The most significant covariates that impacted on mortality were postoperative biliary leaks (HR 2.0 (95\% CI 1.05 - 3.80)), recipient age $>60$ years at time of transplant (HR 2.06 (95\% CI 1.06 - 3.99)), theatre time $>8$ hours (HR 3.13 (95\% CI 1.79 - 5.48)), and hepatic artery thrombosis (HR 5.58 (95\% CI 3.09 - 10.08)). The most common infectious cause of death was invasive fungal infection.

Conclusions. This study demonstrates that outcomes of the adult orthotopic liver transplant programme at WDGMC are comparable with international transplant centres. Management of biliary complications, early hepatic artery thrombosis and post-transplant infections needs to be improved. Access to liver transplantation services is still extremely limited, but can be improved by addressing the national shortage of deceased donors and establishing a national regulatory body for solid-organ transplantation in SA.

S Afr Med J 2018;108(11):929-936. DOI:10.7196/SAMJ.2018.v108i11.13286

There are only two adult liver transplant programmes in sub-Saharan Africa, and both are in South Africa (SA). The absence of these services for a billion people in this region contrasts starkly with widespread access in high-income countries. In SA, the first programme was established in 1988 at Groote Schuur Hospital in Cape Town and the second programme in 2004 at Wits Donald Gordon Medical Centre (WDGMC) in Johannesburg. ${ }^{[1]}$ WDGMC is uniquely situated as a private academic teaching hospital in the Faculty of Health Sciences at the University of the Witwatersrand. The hospital focuses on teaching and training of specialists and sub-specialists and the provision of specialist care, including liver transplantation. Access to the liver transplant programme is based on need and all adults are prioritised for transplantation based on the severity of their illness. Referrals are widely received from state and private facilities.

Survival data on adult orthotopic liver transplants (OLTs) from international programmes have been published. Survival rates differ between middle-income and high-income countries because the volume of transplant procedures is usually much larger in 
high-income countries. The Cape Town programme published a 10-year review (1988 - 1998) of 44 adult OLT procedures with 1- and 5-year patient survival rates of $72 \%$ and $61 \%$, respectively. ${ }^{[1]}$ There are no data for adult liver transplants in SA after that time, despite major changes in the care and available treatment of transplant patients.

\section{Objectives}

To critically review the outcomes, constraints and challenges that persist for the adult liver transplant programme at WDGMC.

\section{Methods}

A retrospective record review was conducted of all adult ( $\geq 18$ years) deceased-donor OLTs performed from the first transplant on 16 August 2004 to 30 June 2016, with a minimum follow-up of 6 months (31 December 2016). Approval for the study was obtained from the Medical Human Research Ethics Committee at the University of the Witwatersrand (ref. no. M140840). Data were extracted and cross-referenced using multiple sources: patient files, regulatory registers, organ procurement records, pathology laboratory and radiology services, surgical operation reports and ward admission records. Vascular and biliary complications were only included if they were confirmed radiologically and required an intervention (radiological and/or surgical). Postoperative biliary and vascular complications were independently reviewed by a radiologist. For all mortalities, cause of death was ascertained from clinical records, registers and postmortem reports, where available.

The following transplant recipient data were collected: age (on day of transplant procedure); gender; population group (black, mixed race, Asian/Indian and white); height; weight; body mass index $\left(\mathrm{BMI}, \mathrm{kg} / \mathrm{m}^{2}\right)$; cause of liver failure; time on wait list prior to transplantation (days); model for end-stage liver disease (MELD) score $^{[2]}$ at time of transplant; $\mathrm{ABO}$ blood group; health status at time of transplant: inpatient/outpatient, diabetes mellitus, vascular disease, ascites; date of transplant; first or repeat transplant; allograft/s received (whole/split liver); operation time; cold ischaemic time; postoperative surgical morbidity: re-exploration by laparotomy, biliary and vascular complications, primary non-function of allograft; biopsy-proven acute rejection (within the first 90 days); and recipient and allograft survival.

The following deceased-donor data were collected: age (on day of donation); gender; population group (as above); height; weight; $\mathrm{BMI}$; $\mathrm{ABO}$ blood group; referral centre; length of hospital stay prior to donation; operation time for organ harvest; and cause of death. Donor data were used to calculate the donor risk index (DRI). ${ }^{[3]}$ All donors were heart-beating and brainstem dead; there was no donation after cardiac death.

Study data were collected and managed using Research Electronic Data Capture (REDCap), which is a secure, web-based application designed to support data capture for research studies hosted at the Faculty of Health Sciences, University of the Witwatersrand. ${ }^{[4]}$

\section{Statistical analysis}

The DRI was calculated according to the formula provided by Feng et al. ${ }^{[3]}$ Percentage missing data have been included in all results in accordance with the Strobe guidelines for observational data. ${ }^{[5]}$ The association between primary sclerosing cholangitis and comorbid diseases was assessed using Fisher's exact test. Overall survival estimates were determined by the KaplanMeier method and there was no adjustment of the survival analyses for any variables. To determine whether there was an improvement in recipient survival over time, based on the premise that the unit would have undergone an initial learning curve, the survival analysis was divided into two eras. To ensure approximately equal numbers of transplants in each group, era 1 was from 16 August 2004 to 30 June 2012 and included 151 cases. Era 2 comprised all transplants performed from 1 July 2012 to 30 June 2016 and included 146 cases. The effect of covariates on unadjusted recipient survival for first transplants in patients with nonacute liver failure (ALF) was determined by Cox proportional hazards regression and included recipient age and BMI at transplant, recipient gender, DRI, allograft type, reci- pient length of hospital stay, operation time, cold ischaemic time, MELD score pre-transplant, health status pre-surgery (diabetes mellitus, ascites), centre experience (era 1 v. era 2 ), postoperative biliary and vascular complications, and cause of chronic liver disease (alcoholic and non-alcoholic steatohepatitis, autoimmune hepatitis, malignancy, primary sclerosing cholangitis, hepatitis B or C). The continuous variables were categorised for this analysis. Data were analysed using SAS version 9.4 (SAS Institute, USA). The 5\% significance level was used.

\section{Results}

Between 16 August 2004 and 30 June 2016, there were 297 adult OLTs performed at WDGMC. Since inception of the programme, there has been a steady growth in the number of transplants performed per year (Fig. 1). While most recipient referrals were from the private sector, the relative proportions from the state sector almost doubled in era $2(16 / 146,11.0 \%)$ compared with era 1 (9/151, 6.0\%). The majority of the procedures performed were liver-only transplants (293/ 297, 98.7\%), and of these 16/293 (5.5\%) were split grafts. There were 3 combined liverkidney (1.0\%), 1 combined liver-heart (0.3\%) and 12 repeat transplants $(4.0 \%)$.

Characteristics of all recipients at the time of the transplant are summarised in Table 1. Overall, the median age of recipients was 51 years, almost two-thirds were male, and the median MELD score was 17 (interquartile range (IQR) 13 - 22). Nine percent of recipients had a MELD score $>30$. The indications for the transplant were ALF in $6.4 \%$ of cases (19/297) and end-stage liver disease (ESLD) in the remainder. Of the 6 patients who presented with druginduced liver failure in the ALF group, 3 were HIV-positive with efavirenz-induced hepatotoxicity.

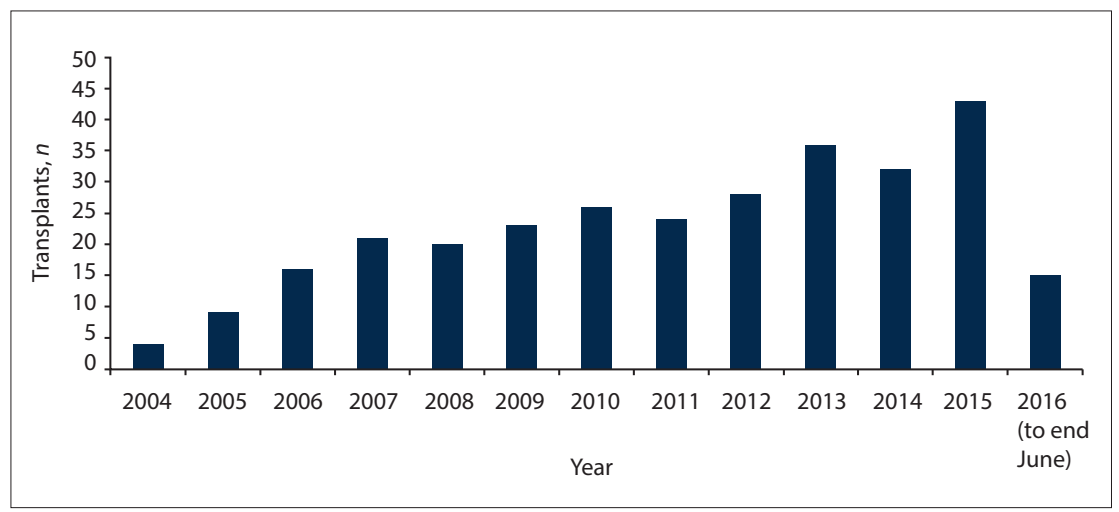

Fig. 1. Adult orthotopic liver transplants performed per annum at Wits Donald Gordon Medical Centre from 16 August 2004 to 30 June 2016. 


\begin{tabular}{|c|c|}
\hline Variable & Overall $(N=297)$ \\
\hline \multicolumn{2}{|l|}{ Referral site, $n(\%)$} \\
\hline State & $25(8.4)$ \\
\hline Private & $272(91.6)$ \\
\hline Age (years), median (IQR) & $51(41-59)$ \\
\hline \multicolumn{2}{|l|}{ Gender, $n(\%)$} \\
\hline Male & $173(58.2)$ \\
\hline Female & $124(41.8)$ \\
\hline \multicolumn{2}{|l|}{ Population group, $n$ (\%) } \\
\hline White & $204(68.7)$ \\
\hline Black & $53(17.8)$ \\
\hline Indian/Asian & $28(9.5)$ \\
\hline Mixed & $8(2.7)$ \\
\hline Missing & $4(1.3)$ \\
\hline \multicolumn{2}{|l|}{ Blood group, $n(\%)$} \\
\hline $\mathrm{O}$ & $138(46.5)$ \\
\hline A & $112(37.7)$ \\
\hline B & $33(11.1)$ \\
\hline $\mathrm{AB}$ & $12(4.0)$ \\
\hline Missing & $2(0.7)$ \\
\hline BMI $\left(\mathrm{kg} / \mathrm{m}^{2}\right)$, median (IQR) $(N=292,98.3 \%)$ & $26(23-31)$ \\
\hline \multicolumn{2}{|l|}{ Disease severity, $n$ (\%) } \\
\hline Ascites, present/missing & $193(65.0) / 5(1.7)$ \\
\hline Diabetes mellitus (type 2 only, no type 1), present/missing & $56(18.9) / 4(1.3)$ \\
\hline Vascular disease (cerebral, cardiac, peripheral), present/missing & $32(10.8) / 24(8.1)$ \\
\hline Hospitalisation, yes/missing & $52(17.5) / 43(14.5)$ \\
\hline Dialysis, yes/missing & $12(4.0) / 4(1.3)$ \\
\hline MELD score, median (IQR) & $17(13-22)$ \\
\hline \multicolumn{2}{|l|}{ MELD score, $n(\%)$} \\
\hline$<10$ & $31(10.4)$ \\
\hline $10-20$ & $168(56.6)$ \\
\hline $21-30$ & $68(22.9)$ \\
\hline$>30$ & $27(9.1)$ \\
\hline Missing & $3(1.0)$ \\
\hline \multicolumn{2}{|l|}{ Cause of ALF, $n(\%)(N=19,6.4 \%)$} \\
\hline Primary non-function of allograft & $8(2.7)$ \\
\hline Drug-induced & $6(2.0)$ \\
\hline Infection & $4(1.4)$ \\
\hline Acute Wilson’s disease & $1(0.3)$ \\
\hline \multicolumn{2}{|l|}{ Cause of ESLD, $n(\%)(N=278,93.6 \%)^{*}$} \\
\hline \multicolumn{2}{|l|}{ Cholestatic (biliary) cirrhosis } \\
\hline Primary sclerosing cholangitis & $74(24.9)$ \\
\hline Primary biliary cirrhosis & $20(6.7)$ \\
\hline Vanishing bile duct syndrome & $6(2.0)$ \\
\hline Missing & $1(0.3)$ \\
\hline \multicolumn{2}{|l|}{ Non-cholestatic cirrhosis } \\
\hline Non-alcoholic steatohepatitis & $58(19.5)$ \\
\hline Alcoholic steatohepatitis & $53(17.8)$ \\
\hline Autoimmune hepatitis & $34(11.4)$ \\
\hline Hepatitis C & $15(5.1)$ \\
\hline Hepatitis B & $12(4.0)$ \\
\hline Cryptogenic & $12(4.0)$ \\
\hline Other $^{\dagger}$ & $6(2.0)$ \\
\hline \multicolumn{2}{|l|}{ Malignancy } \\
\hline Hepatocellular carcinoma & $23(7.7)$ \\
\hline Hepatic epithelioid haemangioendothelioma & $2(0.7)$ \\
\hline
\end{tabular}




\begin{tabular}{|c|c|}
\hline Variable & Overall $(N=297)$ \\
\hline Hepatic embryonal sarcoma & $1(0.3)$ \\
\hline Metastatic liver disease (colorectal cancer) & $1(0.3)$ \\
\hline Cholangiocarcinoma & $3(1.0)$ \\
\hline Ductal carcinoma (other than cholangiocarcinoma) & $1(0.3)$ \\
\hline Missing & $1(0.3)$ \\
\hline \multicolumn{2}{|l|}{ Venous outflow obstruction } \\
\hline Budd-Chiari syndrome & $16(5.4)$ \\
\hline \multicolumn{2}{|l|}{ Metabolic } \\
\hline Alpha-1-antitrypsin deficiency & $5(1.7)$ \\
\hline Haemochromatosis & $4(1.3)$ \\
\hline Wilson's disease & $2(0.7)$ \\
\hline Oxalosis & $2(0.7)$ \\
\hline Erythropoeitic porphyria & $1(0.3)$ \\
\hline PFIC (type 2 - biopsy proven) & $1(0.3)$ \\
\hline
\end{tabular}

In the group with ESLD, the median time on the wait list was 54 days (IQR 23 - 130). As expected, primary sclerosing cholangitis was the most common aetiology (74/297, $24.9 \%$ ), followed by almost equal numbers of alcoholic (53/297, 17.8\%) and non-alcoholic steatohepatitis $(58 / 297,19.5 \%)$. Patients with primary sclerosing cholangitis had a significantly higher prevalence of ulcerative colitis $(26.4 \% ; \quad p<0.0001)$ and Crohn's disease $(9.7 \% ; p<0.0001)$ compared with those who did not have primary sclerosing cholangitis, for whom the prevalences of ulcerative colitis and Crohn's disease were $1.4 \%$ and $0.5 \%$, respectively. Malignancies, most commonly hepatocellular carcinoma, comprised $10.8 \%$ (32/297), with a similar proportion of chronic hepatotropic viral infections (9.4\%, 28/297), of which hepatitis $\mathrm{C}$ was most frequent.

The deceased-donor pool comprised mostly young white males who died from trauma. This was reflected in the relatively low median DRI of 1.61 (IQR 1.37 - 1.90) (Table 2).

Postoperative surgical complications are detailed in Table 3. Primary non-function of the allograft occurred in 8 cases $(2.7 \%)$. Approximately $20 \%$ of patients required an exploratory laparotomy post-procedure. Overall, the most frequent complications were of biliary origin $(62 / 297,20.9 \%)$. The biliary leak rate was $9.1 \%(27 / 297)$ and most leaks occurred within the first 90 days after transplant. Conversely, the biliary stricture rate was $13.1 \%(39 / 297)$ and most occurred after 90 days. By far the most common vascular complication was hepatic artery thrombosis (HAT), with an incidence rate of $3.7 \%(11 / 297)$ in the first 30 days posttransplant.

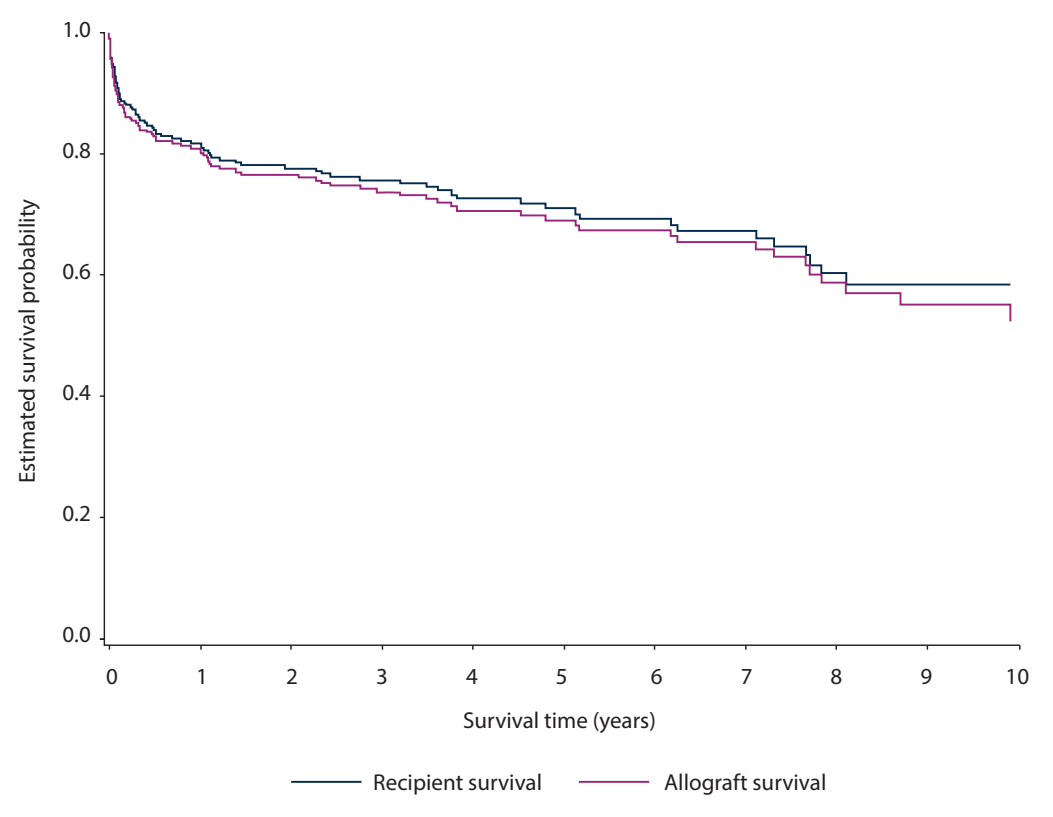

Fig. 2. Unadjusted adult orthotopic liver transplant survival for allograft and recipient at Wits Donald Gordon Medical Centre (first transplant only, non-acute liver failure aetiology, $\mathrm{N}=275$ )

Median follow-up was 3.2 years. Using the Kaplan-Meier method, recipient survival for first transplants for end-stage liver disease $(n=275)$ was estimated at the following intervals: 90 days $=87.6 \%$ (95\% confidence interval (CI) $83.1-91.0), 1$ year $=81.7 \%(95 \%$ CI $76.6-85.8)$, and 5 years $=71.0 \%(95 \%$ CI 64.5 - 76.5). Allograft survival was similar: 90 days $=85.8 \%(95 \%$ CI $81.1-89.4), 1$ year $=$ $81.0 \%(95 \%$ CI $75.8-85.2)$, and 5 years $=$ 69.1\% (95\% CI 62.6 - 74.7) (Fig. 2). While there was improved recipient survival in era 2 compared with era 1 , this was not statistically significant ( $p=0.095$ ) (Fig. 3).

Using proportional hazards regression analysis, the following covariates were associated with a significantly increased risk of mortality: recipient age $>60$ years at time of transplant (compared with age 18 - 39 years) (hazard ratio (HR) 2.06 (95\% CI 1.06 - 3.99)); theatre time $>8$ hours (compared with 6 - 8 hours) (HR 3.13 (95\% CI 1.79 - 5.48)); postoperative biliary leaks (HR 2.0 (95\% CI 1.05 - 3.80)); any vascular complication (HR 3.78 (95\% CI 2.30 6.22)); and HAT (HR 5.58 (95\% CI 3.09 10.08)). There was no significant association with any aetiology of chronic ESLD and postoperative mortality (appendices 1 and 2 , available from the corresponding author on request: june.fabian@mweb.co.za).There was a substantial mortality risk associated 


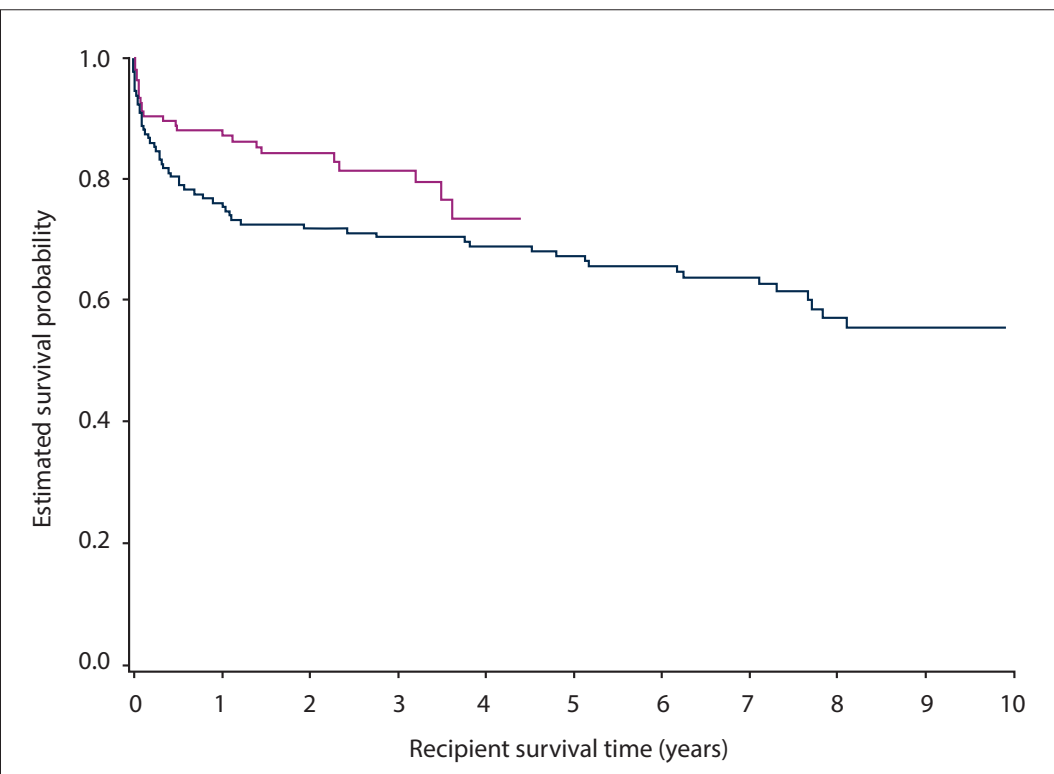

16 August 2004 - 30 June 2012 (era 1)

1 July 2012 - 30 June 2016 (era 2)

Fig. 3. Adult liver transplant recipient and allograft survival at Wits Donald Gordon Medical Centre (first transplant only, non-acute liver failure, $\mathrm{N}=275)$. Recipient survival: era 1: 90 days $=85.2 \%$ (95\% CI 78.2 - 90.0) and 1 year $=76.1 \%(95 \%$ CI 68.1 - 82.2); era 2: 90 days $=90.2 \%(95 \%$ CI $83.8-94.2)$ and 1 year $=87.9 \%(95 \%$ CI $81.0-92.4)$. (CI = confidence interval. $)$

with 'redo' or second transplants (HR 4.6 (95\% CI 2.3 - 9.3)).

Postmortem reports were available for almost half of the recipients who died in the first 90 days (20/47). Infectious aetiologies were the most common primary cause of death (9/20), and a significant contributing factor in 4 additional cases. Allograft failure $(5 / 20)$, pulmonary thromboembolic disease $(2 / 20)$, myocardial ischaemia $(2 / 20)$ and cerebrovascular accident (1/20) comprised the remaining primary causes of death (1 case was undetermined). When infection was cited as the primary cause of death, the lungs $(n=4)$ and gut $(n=4)$ were the most common sources. Fungi were the organisms most commonly identified post mortem, namely Candida $(n=2)$, aspergillosis $(n=4)$, blastomycosis $(n=1)$ and mucormycosis $(n=1)$. It could not be established whether these organisms were identified antemortem.

\section{Discussion}

In the adult OLT programme at WDGMC, patient and graft survival are comparable to local and international transplant centres. The Cape Town programme published a 10-year review (1988 - 1998) of 44 adult OLT procedures with 1 - and 5-year patient survival rates of $72 \%$ and $61 \%$, respectively. ${ }^{[1]}$ The improved survival observed in our programme, $81.7 \%$ at 1 year and $70.0 \%$ at 5 years, is a more contemporary experience and may reflect a combination of advances in immunosuppressive therapy such as the advent of tacrolimus, and improvements in surgical experience with a relatively higher transplant volume. More recently, other middle-income countries such as Thailand, India and Brazil have published similar outcomes. ${ }^{[6-8]}$ Collectively, it is difficult to compare the outcomes of middle-income countries with high-income regions such as Europe and the USA, as the transplant milieu is different and volumes are substantially smaller. However, while early survival rates (90 days and 1 year) do appear to be lower in middle-income countries, survival rates after 1 year are equivalent to high-income regions. ${ }^{[9-11]}$

The most common indication for liver transplant in our study was primary sclerosing cholangitis, followed by nonalcoholic and alcoholic steatohepatitis. This was similar to the findings published from Cape Town, where the three most common indications for liver transplant were postnecrotic and alcoholic cirrhosis, and primary sclerosing cholangitis. ${ }^{[1]}$ In both SA sites, primary sclerosing cholangitis was the cause of ESLD in $22-25 \%$ of liver transplant recipients, compared with 5\% in Europe and $9 \%$ in the USA. ${ }^{[10-12]}$ Cholestatic causes of liver failure are also less frequent indications for liver transplant in Asia, where hepatitis B infection is the predominant cause of ESLD. ${ }^{[12]}$ Internationally, post-transplant survival for patients with ESLD due to primary sclerosing cholangitis is usually better than for other causes, but this was not demonstrated in our study (appendix 1 available from the corresponding author on request: june.fabian@mweb.co.za)..10-12] One explanation may be that our sample size was relatively small. As an infectious cause of ESLD, hepatitis C (5.1\%) was more common than hepatitis B $(4.0 \%)$, which is unexpected in SA but may be explained by the predominance of white OLT recipients in this cohort.

The emergent cases of ALF secondary to fixed-dose combination antiretroviral therapy (ART) for treatment of HIV infection deserve mention. The spectrum of histopathological changes in patients presenting with drug-induced liver injury secondary to ART shows considerable variation. Biopsies in some patients show features of chronic hepatitis, including portal inflammation with or without lobular inflammation, and variable fibrosis, while in others the pathological injury is much more severe. Many patients recover with interruption of treatment, but in severe cases this complication can be catastrophic as access to liver transplantation is limited. The implications of ALF caused by fixeddose combinations of ART are particularly relevant as SA has the largest HIV treatment programme in the world.

Biliary complications are an important cause of postoperative morbidity and mortality, and the international incidence varies from $5 \%$ to $25 \% .^{[13,14]}$ In our programme, the incidence of all biliary complications was relatively high (20.9\%) (Table 1). Reported incidence rates for biliary leaks and strictures range from 5\% to $10 \%$ and $9 \%$ to $12 \%$, respectively. ${ }^{[14]}$ Our results were consistent with these findings for biliary leaks (9.1\%) and strictures (13.1\%) (Table 3).

HAT is a dreaded complication of liver transplantation, with most cases occurring in the early post-transplant period. There is no standard definition of early HAT (eHAT), ranging from within 2 weeks to 100 days after liver transplantation. In a systematic review that defined eHAT as occurring within the first 2 months of transplant, a worldwide decline in incidence rates over time has been demonstrated, dropping to $2.9 \%$ in adults in high-volume centres. Our eHAT rate of $3.7 \%$ was higher than the rates observed in high-volume centres but comparable to rates observed in other lowvolume centres $(5.8 \%)$. $^{[15]}$

Based on a limited autopsy series of deaths that occurred in the first 90 days, sepsis was unequivocally the most common primary cause of death, and the most frequent organisms identified post mortem 


\begin{tabular}{|c|c|}
\hline Variable & Overall $(N=297)$ \\
\hline Age (years), median (IQR) $(N=291,98.0 \%)$ & $34(21-45)$ \\
\hline \multicolumn{2}{|l|}{ Population group, $n(\%)$} \\
\hline White & $240(80.8)$ \\
\hline Black & $23(7.75)$ \\
\hline Mixed & $23(7.75)$ \\
\hline Indian/Asian & $8(2.7)$ \\
\hline Missing & $3(1.0)$ \\
\hline \multicolumn{2}{|l|}{ Gender, $n(\%)$} \\
\hline Male & $179(60.3)$ \\
\hline Female & $118(39.7)$ \\
\hline BMI $\left(\mathrm{kg} / \mathrm{m}^{2}\right)$, median (IQR) $(N=273,91.9 \%)$ & $25.5(4.5)$ \\
\hline \multicolumn{2}{|l|}{ Blood group } \\
\hline $\mathrm{O}$ & $170(57.2)$ \\
\hline A & $100(33.7)$ \\
\hline B & $24(8.1)$ \\
\hline $\mathrm{AB}$ & $3(1.0)$ \\
\hline \multicolumn{2}{|l|}{ Cause of death } \\
\hline Trauma & $158(53.2)$ \\
\hline CVA & $109(36.7)$ \\
\hline Anoxia & $9(3.0)$ \\
\hline Other & $19(6.4)$ \\
\hline Missing & $2(0.7)$ \\
\hline \multicolumn{2}{|l|}{ Allocation of deceased-donor organ } \\
\hline Regional & $193(65.0)$ \\
\hline National & $104(35.0)$ \\
\hline \multicolumn{2}{|l|}{ DRI, $n(\%)$} \\
\hline$\leq 1.00$ & $1(0.3)$ \\
\hline $1.01-1.20$ & $23(7.7)$ \\
\hline $1.21-1.40$ & $51(17.2)$ \\
\hline $1.41-1.60$ & $48(16.2)$ \\
\hline $1.61-1.80$ & 49 (16.5) \\
\hline $1.81-2.00$ & $38(12.8)$ \\
\hline$>2.00$ & $48(16.2)$ \\
\hline Missing & $39(13.1)$ \\
\hline DRI, median (IQR) & $1.61(1.37-1.90)$ \\
\hline
\end{tabular}

were fungi. This has been described previously and raises some pertinent considerations for clinical practice such as whether certain high-risk individuals should receive antifungal prophylaxis, for example those undergoing 'redo' transplants or with a pretransplant MELD score of $\geq 20 .{ }^{[16]}$ There are also diagnostic challenges because fungal infections may be missed without a tissue sample, such as a lung or liver biopsy specimen. ${ }^{[17]}$ We currrently have a high index of suspicion for fungal infection in our programme and use trends in beta-D glucan and galactomannan levels to initiate broadspectrum antifungal therapy. Where possible, an attempt is made to obtain biopsy material to confirm the diagnosis of invasive fungal infection.

Despite favourable outcomes, the adult OLT programme at WDGMC faces numerous challenges. For countries north of our borders, there is no access to liver transplantation and this is unlikely to change in the immediate future. Both the SA transplant programmes are located in large urban cities, making access difficult for those who live in semi-urban and rural areas. Further restrictions to access are imposed by a two-tiered healthcare system that favours the private sector and a national paucity of organ donors. Although the liver transplant centre in Cape Town is located in the state sector, the volume of transplants performed annually is relatively low. Without active, high-volume participation by state hospitals in solid-organ transplantation, access to these services will remain limited. The hybrid programme at WDGMC makes provision for access to liver transplantation based on need, regardless of 'payer' status. This reflects an evolution of policy, based on the recognition that expansion of transplant services in the state sector has been slow and liver transplantation is a low-demand but resource- and costintensive healthcare service. The increasing number of state patients seen in era 2 reflects this change and is welcomed.

The number of transplants performed annually at WDGMC is not limited by capacity or resources, but rather by a dearth of donors. This highlights one of the greatest barriers to increasing solid-organ transplant volumes in SA and can only be addressed if a multifaceted approach is fully endorsed by national government for: (i) widespread public engagement and education about organ donation; (ii) the establishment of active organ procurement programmes in all hospitals; (iii) developing more transplant centres; and (iv) expanding the deceased and living organ donor pool. 


\begin{tabular}{|c|c|}
\hline Complication & Overall $(N=297)$ \\
\hline \multicolumn{2}{|c|}{ Primary non-function of allograft, $n(\%)$} \\
\hline Yes & $8(2.7)$ \\
\hline No & $289(97.3)$ \\
\hline \multicolumn{2}{|l|}{ Re-exploration (via laparotomy), $n$ (\%) } \\
\hline Yes & $56(18.8)$ \\
\hline No & $239(80.5)$ \\
\hline Missing & $2(0.7)$ \\
\hline \multicolumn{2}{|l|}{ Vascular complication, $n(\%)$} \\
\hline Yes & $39(13.1)$ \\
\hline No & $257(86.6)$ \\
\hline Missing & $1(0.3)$ \\
\hline \multicolumn{2}{|c|}{ Type of vascular complication $(N=39,13.1 \%), n(\%)^{*}$} \\
\hline \multirow[t]{2}{*}{ Portal vein thrombosis } & $11(28.2)$ \\
\hline & 5 early ( $\leq 30$ days), 6 late ( $>30$ days) \\
\hline \multirow[t]{2}{*}{ Portal vein stenosis } & $2(5.1)$ \\
\hline & 0 early, 2 late \\
\hline \multirow[t]{2}{*}{ Inferior vena cava thrombosis } & $3(7.7)$ \\
\hline & 2 early, 1 late \\
\hline \multirow[t]{2}{*}{ Inferior vena cava stenosis } & $3(7.7)$ \\
\hline & 0 early, 3 late \\
\hline \multirow[t]{2}{*}{ Hepatic artery thrombosis } & $19(48.7)$ \\
\hline & 11 early, 8 late \\
\hline \multirow[t]{2}{*}{ Hepatic artery stenosis } & $3(7.7)$ \\
\hline & 1 early, 2 late \\
\hline \multirow[t]{2}{*}{ Hepatic artery pseudoaneurysm } & $2(5.1)$ \\
\hline & 1 early, 1 late \\
\hline Hepatic artery rupture & $1(2.6)$ \\
\hline \multicolumn{2}{|l|}{ Biliary complication, $n(\%)$} \\
\hline Yes & $62(20.9)$ \\
\hline No & $235(79.1)$ \\
\hline \multicolumn{2}{|c|}{ Type of biliary complication $(N=62,20.9 \%), n(\%)^{*}$} \\
\hline \multirow[t]{2}{*}{ Biliary leak } & $27(43.6)$ \\
\hline & 25 early ( $\leq 90$ days), 2 late ( $>90$ days) \\
\hline \multirow[t]{2}{*}{ Biliary stricture } & $39(62.9)$ \\
\hline & 12 early, 27 late \\
\hline \multicolumn{2}{|c|}{ Acute biopsy-proven rejection of allograft, $n$ (\%) } \\
\hline Yes & $22(7.4)$ \\
\hline No & $275(92.6)$ \\
\hline
\end{tabular}

Transplantation programmes require substantial resources, and prioritisation of these services within the national health agenda can be problematic, particularly in middle-income countries. The growth of such services may only be ethically justifiable if the outcomes achieved are comparable to an accepted standard. Auditing local practice as part of the governance process in each transplant unit, a national liver transplant registry, and establishing a national regulatory body for solid-organ transplantation would be appropriate first steps.

\section{Study limitations}

This study has some limitations. It was retrospective and there were missing data, particularly regarding post-transplant infection and early v. late causes of death. Most recipient referrals were from the private sector, so this sample cannot be regarded as representative of the SA population. However, this research has highlighted areas for improvement in our clinical practice, such as reducing biliary and vascular complications and addressing antifungal prophylaxis in high-risk individuals. It also exposes persistent systemic inequities that compromise access to this form of care for most South Africans and demonstrates the complexities of providing liver transplantation services in a middle-income country, which is relatively wellresourced compared with other sub-Saharan African countries.

\section{Conclusions}

In this study, the outcomes of the adult liver transplant programme at WDGMC in Johannesburg were comparable with international centres. Primary sclerosing cholangitis was the most common cause of chronic ESLD, which concurs with similar findings from Cape Town, but differs from international findings in the East and the West. Risk factors associated with increased mortality were recipient age $>60$ years at the time of transplant, operation time $>8$ hours, development of postoperative biliary leaks and vascular complications, particularly hepatic artery thrombosis. The biliary 
complication and eHAT rates were higher than those seen in highvolume centres and remain areas for improvement. Inequities in access to care and low donor rates remain significant challenges for liver transplantation in SA.

\section{Declaration. None.}

Acknowledgements. We thank the clinicians and transplant support staff who willingly facilitated access to records; Victoria Masilo, Masupha Adoro, Thendo Muhali, Sharon Obisie-Orlu, Mozammmil Rehman and Jennifer Cronin for data capture; the patients who have undergone transplantation; and the donor families who, at their time of loss, generously consented to the donation of organs from their loved ones. Author contributions. JF: conceptualisation, data collection and data integrity, rewriting subsequent drafts of the article, collating comments and editing the final draft of the article, submission of the article; ES: conceptualisation, provision of clinical data, editing the final draft of the article; PEB: review of radiological complications, provision of radiological and clinical data; HM: conceptualisation, creation of the research database, data collection and data integrity; PG: statistical analysis, editing the final draft of the article; $A B$ : conceptualisation, writing of the first draft, editing the final draft of the article; MJH: provision of histopathological and postmortem biopsy data, editing the final draft of the article; SPN: provision of histopathological data, editing the final draft of the article; HE: data collection, editing the final draft of the article; AM: provision of clinical data, editing the final draft of the article: BB: provision of clinical data, editing the final draft of the article; BS: provision of clinical data, editing the final draft of the article; JL: provision of clinical data, editing the final draft of the article; RB: provision of clinical data, editing the final draft of the article; JFB: oversight as the senior author, conceptualisation, provision of clinical data, editing the final draft of the article.

Funding. We thank the WDGMC for financial and infrastructural support. Conflicts of interest. None.
1. Botha J, Spearman C, Millar A, et al. Ten years of liver transplantation at Groote Schuur Hospital. S Afr Med J 2000;90(9):880-883.

2. Desai NM, Mange KC, Crawford MD, et al. Predicting outcome after liver transplantation: Utility of the model for end-stage liver disease and a newly derived discrimination function. Transplantation 2004;77(1):99-106. https://doi.org/10.1097/01.TP.0000101009.91516.FC

3. Feng S, Goodrich N, Bragg-Gresham J, et al. Characteristics associated with liver graft failure: The concept of a donor risk index. Am J Transplant 2006;6(4):783-790. https://doi.org/10.1111/j.16006143.2006.01242.x

4. Vandenbroucke JP, von Elm E, Altman DG, et al. Strengthening the Reporting of Observational Studies in Epidemiology (STROBE): Explanation and elaboration. Int J Surg 2014;12(12):1500-1524. https://doi.org/10.1016/j.ijsu.2014.07.014

5. Sirivatanauksorn Y, Kongkaewpaisan N, Pongpaibul A, et al. Outcomes of orthotopic liver transplantation in non-malignant end-stage liver diseases. Transplant Proc 2014;46(3):778-781. transplantation in non-malignant end-stage liver

6. Meirelles Júnior RF, Salvalaggio P, Rezende MB, et al. Liver transplantation: History, outcomes and perspectives. Einstein (Sao Paulo) 2015;13(1):149-152. https://doi.org/10.1590/S167945082015RW31647

7. Saha A, Naidu C, Ramesh G, et al. Liver transplantation in Indian Armed Forces - initial experience. Med J Arm Forces India 2012;68(2):110-117. https://doi.org/10.1016/S0377-1237(12)60018-5

8. Jain A, Reyes J, Kashyap R, et al. Long-term survival after liver transplantation in 4,000 consecutive patients at a single center. Ann Surg 2000;232(4):490-500.

9. Adam R, Karam V, Delvart V, et al. Evolution of indications and results of liver transplantation in Europe: A report from the European Liver Transplant Registry (ELTR). J Hepatol 2012;57(3):675688. https://doi.org/10.1016/j.jhep.2012.04.015

10. Busuttil RW, Farmer DG, Yersiz H, et al. Analysis of long-term outcomes of 3200 liver transplantations over two decades: A single-center experience. Ann Surg 2005;241(6):905-918. https://doi.org/10.1097/01.sla.0000164077.77912.98

11. Roberts MS, Angus DC, Bryce CL, Valenta Z, Weissfeld L. Survival after liver transplantation in the United States: A disease-specific analysis of the UNOS database. Liver Transpl 2004;10(7):886-897. https://doi.org/10.1002/lt.20137

12. Shukla A, Vadeyar H, Rela M, Shah S. Liver transplantation: East versus West. J Clin Exp Hepatol 2013;3(3):243-253. https://doi.org/10.1016/.j.jceh.2013.08.004

13. Pascher A, Neuhaus P. Biliary complications after deceased-donor orthotopic liver transplantation. J Hepatobiliary Pancreat Surg 2006;13(6):487-496. https://doi.org/10.1007/s00534-005-1083-z

14. Gastaca M. Biliary complications after orthotopic liver transplantation: A review of incidence and risk factors. Transplant Proc 2012;44(6):1545-1549. https://doi.org/10.1016/j.transproceed.2012.05.008

15. Bekker J, Ploem S, de Jong K. Early hepatic artery thrombosis after liver transplantation: A systematic review of the incidence, outcome and risk factors. Am J Transplant 2009;9(4):746-757. https://doi. org/10.1111/j.1600-6143.2008.02541.x

16. Cuervas-Mons V, Martinez AJ, Dekker A, Starzl TE, van Thiel DH. Adult liver transplantation: An analysis of the early causes of death in 40 consecutive cases. Hepatology 1986;6(3):495-501.

17. Saliba F, Delvart V, Ichai P, et al. Fungal infections after liver transplantation: Outcomes and risk factors revisited in the MELD era. Clin Transplant 2013;27(4):E454-E461. https://doi.org/10.1111/ ctr.12129

Accepted 25 April 2018. 